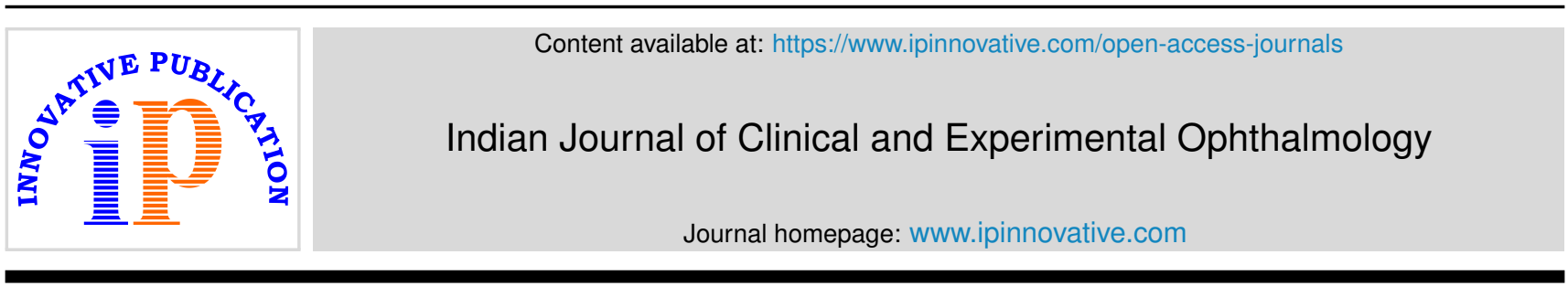

Original Research Article

\title{
Prevalence of meibomian gland dysfunction in patient's who are prone to computer vision syndrome
}

\author{
Prashant $\mathbf{C ~ N}^{\mathbf{1}}$, Rohini Patil ${ }^{1, *}$ \\ ${ }^{1}$ Dept. of Ophthalmology, Dr. B.R Ambedkar Medical College, Bangalore, Karnataka, India
}

\section{A R T I C L E I N F O}

\section{Article history:}

Received 23-01-2020

Accepted 15-04-2020

Available online 30-09-2020

\section{Keywords:}

Meibomian gland Dysfunction

Dry eye disease

Computer vision syndrome

Ocular irritation

\begin{abstract}
A B S T R A C T
Background: Using computer for prolonged time led to the users at greater health risk of computer vision syndrome (CVS). Computer vision syndrome is the leading occupational health problem of the twenty-first century. About 70 percent of computer users are suffered from CVS. Thus aim of this study was to evaluate the meibomian gland dysfunction in computer users.

Materials and Methods: A self-administered questionnaire was used to collect demographic data, symptoms of CVS, detail of computer usage, potential risk factor and types of tasks performed by the computer users. Data was analyzed using statistical package for social sciences software version 14 . Descriptive data was presented as mean $+/$ - standard deviation. Significance of association of meibomian Gland Dysfunction (MGD) with Computer Vision Syndrome (CVS) was tested using chi square test and correlation was tested using Pearson correlation test.

Result: Computer vision syndrome was present in $80 \%$ of subjects. MGD was present in $65 \%$ of the patient diagnosed to have computer vision syndrome. Chi square test for association was statistically significant ( $\mathrm{P}$ value $<0.05)$.

Conclusion: MGD is one of the multifactorial causes for dry eyes in patients prone to the development of computer vision syndrome and should be specifically looked for and treated to give better symptomatic relief to these patients. To explore meibomian gland dysfunction may determine the severity of dry eye condition in computer users.
\end{abstract}

(C) 2020 Published by Innovative Publication. This is an open access article under the CC BY-NC license (https://creativecommons.org/licenses/by-nc/4.0/)

\section{Introduction}

At presentmost of the people are suffering from a variety of ocular symptoms related to computer use. Symptoms like eye strain, irritation, blurred vision and diplopia combined these referred to as computer vision syndrome.

Dry eye is the major contributor to computer vision syndrome symptoms. It is a group of visual symptoms experienced in relation to the use of computers resulting in reduced productivity at work and reduce quality of life.

User of the computer are subject to visual problems these effects tend to be significant as the exposure time per day and duration increases per year. Computer usage raises the number of dry eye individuals and increase the severity of

\footnotetext{
* Corresponding author.

E-mail address: drronupatil@gmail.com (R. Patil).
}

symptoms.

Symptoms include ocular irritation, eye fatigue, blurred vision, red eyes, burning sensation, epiphora, headache, photophobia, difficulty in accommodation.

Dry eye disease is a multifactorial disease of the ocular surface characterized by a loss of homeostasis of the tear film, and accompanied by ocular symptoms, in which tear film instability and hyper-osmolarity, ocular surface inflammation and damage, and neurosensory abnormalities play etiological roles. ${ }^{1-3}$

National eye institute international eye workshop (DEWS) IN 1995 defined dry eye as a disorder of the tear film due to reduced tear production or excessive tear evaporation, which causes damage to the interpalpebral ocular surface and is associated with symptoms of ocular discomfort and /visual symptoms. 
In the global there is increasing development of digital device which is related to use of computer which is associated with higher incidence of ocular discomfort and other systemic and mental health problems. ${ }^{4}$

The use of computer that causes ocular symptoms which is an important health issue this may interfere with quality of life, work activity and productivity. ${ }^{5}$

The duration of computer work hours especially for more than 4 hours daily, was observed to be associated with high risk for development of dry eye disease. ${ }^{6}$ The ocular symptoms complained by computer workers which is correlated with the dysfunction of meibomian glands ${ }^{7}$ this was considered as one of the major causes of ocular complaints, inflammation and other ocular surface disorders. $^{8}$

Meibomian gland dysfunction (MGD) is defined as the changes in the meibomian gland which is a chronic, diffuse abnormality of the meibomian gland, commonly presented by terminal duct obstruction, hypersecretory and hyposecretory changes in the glandular secretion. It causes alteration of the tear film, ocular symptoms like irritation, inflammation, and ocular surface disease. Clinically, MG changes can manifest as gland atrophy, orifice obstruction, changes in meibum and eyelid vascularity. The most common type of MGD is obstructive type. ${ }^{9}$

The meibomian gland synthesis and secrete lipids in the eyelid. Which maintain superficial tear film layer, which is responsible for the healthy ocular surface through reducing tear evaporation.

MGD responsible for the main reason for evaporative dry eye, and may be correlated with aqueous deficient dry eye.

The use of computer that make us keep eyes open widely has been recognized to decrease the frequency of blinking and accelerate tear evaporation.

An important feature in the pathogenesis of MGD is hyper keratinization of the ducts. which cause stenosis of the duct and its orifice and result in gland dysfunction. ${ }^{10}$ There is alteration in the lipid secreted by meibomian glands. ${ }^{11}$ The triglyceride fraction that is responsible for the transition from polar to nonpolar lipid is also altered. ${ }^{12}$ Free fatty acid cause ocular toxicity, irritation, foam formation and destabilization of the tear film. ${ }^{13}$

\section{Diagnosis of MGD}

\subsection{Conduct of test}

1. Under slit-lamp observation, gland morphology and expressed liquid are examined.

2. The appearance of the liquid is recorded in terms of clarity, viscosity and colour.

\subsection{Grading}

Viscosity is graded as:
1. Free-flowing liquid/clear.

2. Free flowing but with slight increase in viscosity/cloudy.

3. Noticeably thickened/cloudy particulate.

4. Toothpaste consistency.
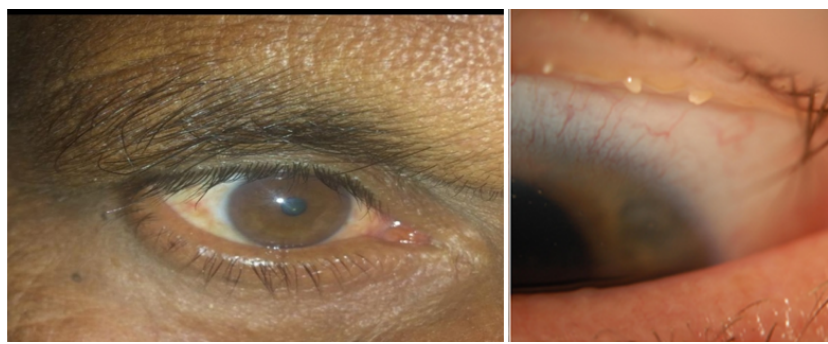

Fig. 1:

\subsection{Purpose of the study}

To study the prevalence of meibomian gland dysfunction in patient who are prone to or diagnosed to have computer vision syndrome (software professionals).

\section{Materials and Methods}

\subsection{Inclusion criteria}

300 subjects were included in the study who worked in front of computer for more than 6 hours per day, 5 days a week for at least 12 months.

\subsection{Exclusion criteria}

Patients having any ocular or systemic conditions associated with dry eyes including lens wear, history of use of ocular medication, anatomical abnormality of the eyelid (ectropion).

A self-administered questionnaire was used to collect demographic data, symptoms of CVS, detail of computer usage, potential risk factor. The types of tasks performed by the computer users are word processing, spreadsheet processing, data entry and processing, preparing learning and teaching materials, and reading texts on computer. The study subjects were asked to report any eye symptoms experienced while on continuous computer work either at office or home within the past 12-month duration.

A multistage random sampling technique was used to select participants from governmental offices and private multinational companies. We have used two stages to select the final study participants in this study.

Presence of any one of the CVS symptoms, either intermittently or continuously at least week considered as presence of Computer vision syndrome. MGD was diagnosed based on gland morphology, ability to express and altered secretion. 
Statistical analysis was done using Statistical Package for Social Sciences (SPSS) software, version 14. data was presented as mean \pm standard deviation. Significance of association of MGD with CVS was tested using Chi square. Correlation was tested using Pearson correlation test.

\section{Result}

Mean age +/- standard deviation $32.4+/-5.1$ years. CVS was present in $82 \%$ of subjects (240 individuals). MGD was present in $75 \%$ of the patients diagnosed to have CVS (156 individuals). Chi square test for association was statistically significant $(P$ value $<0.05$ ). Signs of MGD showed a significant correlation with CVS ( $p$ value $<0.05$ ). Highpaid workers can have a better access to health care, which could have alleviated their symptoms. On top of that, these groups were managers and executives in this study, who are engaged in less repetitive work such frequents statistics checking in the electronic devices. A chi-square test shows highly paid computer users took break significantly higher than their counterparts $\left(X^{2}=5.6, p\right.$ value $\left.=0.07\right)$, which supported the above. Their daily duration of computer use was also significantly less than low-paid computer users (Pearson correlation test between income and computer exposure time: $\mathrm{r}=-0.24$, $\mathrm{p}$ value $\leq 0.001$ ).

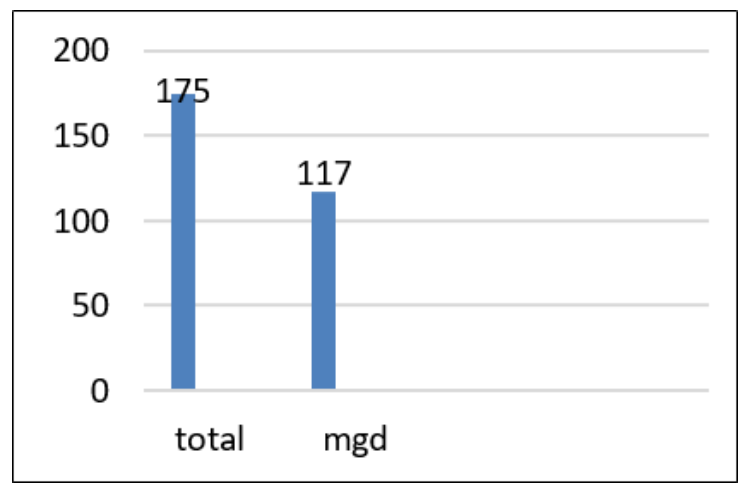

Fig. 2: Computer users with MGD

\section{Discussion}

Prolong and continuous use of computer for long duration more than 4 hours per day is found to have severe ocular symptoms like blurring of vision, itching, redness especially in those patients who are using computer and similar device for long duration per day. Majority was carrying the symptoms for $<4$ days and $>1$-month duration. The statistical analysis revealed severe ocular symptoms in the majority of objects present in those who are expose to computer permanent and prolong duration. There were 94.3\% knew the bad effect of computer use on the eyes. Most common ocular symptoms resulted from prolong period of using computer were estimated. The odds of

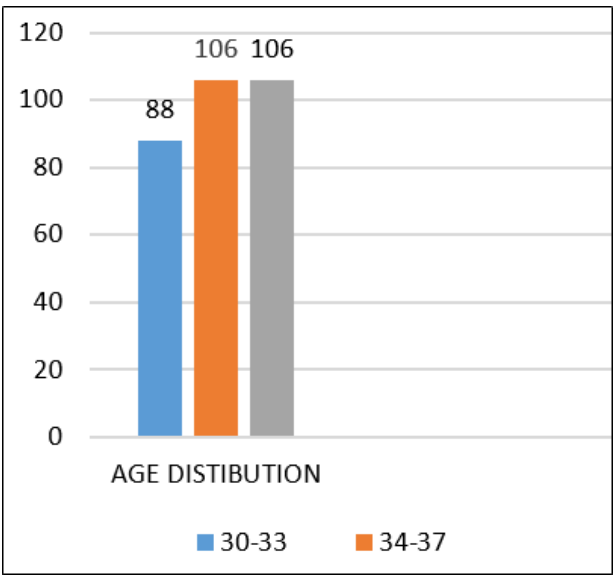

Fig. 3: Age distribution

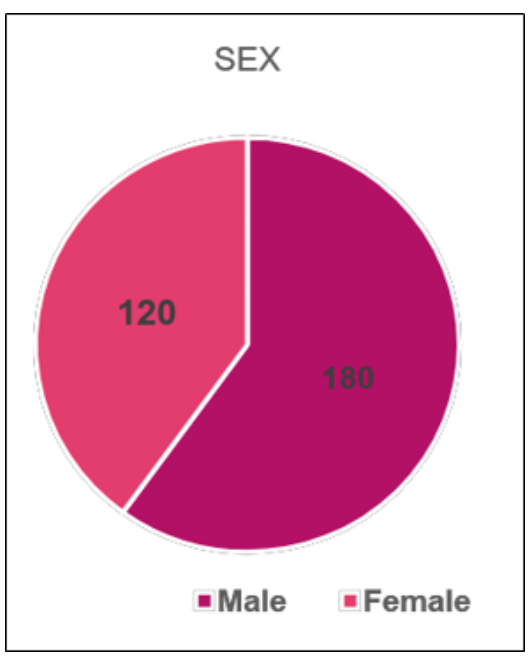

Fig. 4: Sex distribution

developing CVS were higher among computer users who had less frequent or no break.

Highly paid computer users were less likely to develop CVS than their low-paid counterparts. This might be due to the fact that high-paid computer users may have greater opportunity to use antiglare and good computers that could reduce the development of CVS. Conversely, low-paid ones were suffering from this disease because they could not afford these facilities. High-paid computer users might have good awareness on computer ergonomics and can optimize safe duration of computer exposure.

Pimenidi MK, et al it reviews etiology and pathogenesis of dry eye syndrome due to MGD It is showed that blink rate having great influence on meibomian gland functioning and computer vision syndrome development. Occupational safety and health administration of the US government (OSHA) has defined Computer vision syndrome as a of complex eye and vision problems that are experienced during and related to use of computer. This disease seems 
to be growing rapidly $93 \%$ workers using computer from $>3$ hours per day.

\section{Conclusion}

MGD is a main risk factor for the ocular symptoms in prolong computer user. It causes rapid evaporation of the tear film, which increase symptoms of dry eye in CVS patients. The main cause of prevalence of MGD in computer users are incomplete and infrequent blinking and low humidity conditions like use of air conditioning.

MGD is one of the multifactorial causes for the development of dry eyes in patients prone to the computer vision syndrome and should be carefully looked for the ocular symptoms and proper treatment should be given for best symptomatic relief. There is correlation between ocular surface disease (MGD) and Computer vision syndrome.

Hence, optimizing the exposure time and improving the awareness of users by rigorous training and management support are important to tackle the problem. In the future, it is recommended to determine the additive or synergistic effect of using smartphone and computer tablets on CVS on or off working time. Taking a break was not significantly associated with prevalence of CVS as demonstrated by present data. Reddy et al. reported a similar finding

Prolong use of Computer increase the number of dry eye suffers and increase the severity of the symptoms. Study shows high incidence of MGD in prolong computer users. Prolong and Continuous use of computer for long hours duration more than 4 hours per day found to have severe problem of vision and other ocular symptoms like redness, itching, irritation.

\section{Source of Funding}

None.

\section{Conflict of Interest}

None.

\section{References}

1. Definition and classification of dry eye disease: report of the
Definition and Classification Subcommittee of the International Dry Eye Workshop. Ocul Surf. 2007;5(2):75-92.

2. Dorennavar L, Maurya RP, Singh VP, Singh MK, Sharma K, Sharma $\mathrm{R}$. The role of Rebamipide ophthalmic suspension in management of dry eye disease. Indian J Clin Expl Ophthalmol. 2015;1(4):191-6.

3. Maurya RP, Singh VP, Chaudhary S, Roy M, Srivastav T. Prevalence of severe dry eye disease in postmenopausal women in North India: A teaching hospital study. Indian J Obstet Gynecol Res. 2019;6(1):94-6.

4. Ye Z, Abe Y, Kusano Y, Takamura N, Eida K, Takemoto T, et al. The Influence of Visual Display Terminal Use on the Physical and Mental Conditions of Administrative Staff in Japan. J Physio Anthropol. 2007;26(2):69-73.

5. Nelson JD, Shimazaki J, del Castillo JMB, Craig JP, McCulley JP, Den S, et al. The International Workshop on Meibomian Gland Dysfunction: Report of the Definition and Classification Subcommittee. Invest Ophthalmol Vis Sci . 2011;52(4):1930-7.

6. Uchino M, Uchino Y, Dogru M, Kawashima M, Yokoi N, Komuro A, et al. Dry eye disease and work productivity loss in visual display users: The osaka study. Am J Ophthalmol. 2014;157(2):294-300.

7. Uchino M, Schaumberg DA, Dogru M, Uchino Y, Fukagawa K, Shimmura S, et al. Prevalence of Dry Eye Disease among Japanese Visual Display Terminal Users. Ophthalmol. 2008;115(11):1982-8.

8. Fenga C, Aragona P, Cacciola A, Spinella R, Nola CD, Ferreri F, et al. Meibomian gland dysfunction and ocular discomfort in video display terminal workers. Eye. 2008;22(1):91-5.

9. Shimazaki J, Sakata M, Tsubota K. Ocular surface changes and discomfort in patients with meibomian gland dysfunction. Arch Ophthalmol. 1995;113:1266-70.

10. Gutgesell VJ, Stern GA, Hood CI. Histopathology of Meibomian Gland Dysfunction. Am J Ophthalmol. 1982;94(3):383-7.

11. McCulley JP, Shine WE. Meibomian Gland Function and the Tear Lipid Layer. Ocular Surf. 2003;1:97-106.

12. Shine WE, McCulley JP. Meibomian Gland Triglyceride Fatty Acid Differences in Chronic Blepharitis Patients. Cornea. 1996;15(4):3406.

13. Jester JV, Nicolaides N, Palvalgyi IK, Smith RE. Meibomian gland dysfunction 2 the role of keratinization in a rabbit model of MGD. Histologic and ultra-structural investigation. Invest Ophthalmol Vis Sci. 1989;30:936.

\section{Author biography}

Prashant C N Associate Professor

Rohini Patil Post Graduate

Cite this article: Prashant C N , Patil R. Prevalence of meibomian

gland dysfunction in patient's who are prone to computer vision syndrome. Indian J Clin Exp Ophthalmol 2020;6(3):391-394. 